\title{
GROWTH OF THE RIGHT VENTRICLE AFTER SUCCESSFUL TRANSCATHETER PULMONARY VALVOTOMY IN NEONATES AND INFANTS WITH PULMONARY ATRESIA AND INTACT VENTRICULAR SEPTUM
}

Caroline Ovaert, MD

Shakeel A. Qureshi, FRCP

Eric Rosenthal, MD, MRCP

Edward J. Baker, MD, FRCP

Michael Tynan, MD, FRCP
Objectives: Since 1990, transcatheter pulmonary valvotomy has become an alternative to surgical valvotomy in the management of neonates and infants with pulmonary atresia and intact ventricular septum. We sought to determine whether right ventricular growth after transcatheter pulmonary valvotomy is commensurate with body growth. Methods: Laser or radiofrequency-assisted balloon valvotomy was attempted in 12 neonates and infants with pulmonary atresia and intact ventricular septum. Tricuspid and mitral valve dimensions were measured retrospectively on the crosssectional echocardiograms performed before the procedure and during follow-up. Z-values were used to standardize tricuspid valve dimensions with body size. Results: The atretic pulmonary valve was successfully perforated and dilated in nine of 12 patients. Five of these nine patients required additional transcatheter or surgical procedures to augment the pulmonary blood flow. Of six survivors, five are regularly followed up with a median follow-up of 60 months (range 37 to 68 months). All five have two-ventricle circulation, two of the five patients requiring surgical enlargement of the right ventricular outflow tract with or without closure of the atrial septal defect. Echocardiographic tricuspid valve dimensions and $Z$-values before transcatheter valvotomy tended to be smaller in the patients who died than in the survivors. In the survivors, the absolute tricuspid valve dimensions increased after valvotomy but the $\mathrm{Z}$-values tended to decrease or stayed constant. Conclusions: Transcatheter valvotomy is a good alternative to surgical valvotomy in patients with pulmonary atresia and intact ventricular septum. Two-ventricle circulation can be achieved despite subnormal right ventricular growth. (J Thorac Cardiovasc Surg 1998;115:1055-62)
$D^{2}$ espite important improvements over the past 30 years in the treatment strategies for neonates with pulmonary atresia and intact ventricular septum, mortality and morbidity remain significant. ${ }^{1-5}$ Abnormalities of the coronary artery circulation together with right ventricular hypoplasia are considered adverse prognostic factors and may make biventricular repair difficult if not impossible. 1, 5-10 $^{-10}$ The early establishment of right ventricle-pulmo-

From the Department of Paediatric Cardiology, Guy's Hospital, London, United Kingdom.

Received for publication Feb. 3, 1997; revisions requested March 11, 1997; revisions received Nov. 11, 1997; accepted for publication Nov. 11, 1997.

Address for reprints: Shakeel Qureshi, MD, Department of Paediatric Cardiology, 11th Floor, Guy's Tower, Guy's Hospital, St. Thomas Street, London SE1 9RT, United Kingdom. Copyright (c) 1998 by Mosby, Inc.

0022-5223/98 $\$ 5.00+0 \quad \mathbf{1 2 / 1 / 8 7 5 2 6}$ nary artery continuity and antegrade flow, either alone or combined with a systemic-pulmonary artery shunt, may promote the growth of the right ventricle, with the future aim that a normal or near normal right ventricle would support a two-ventricle circulation., ${ }^{61-17}$ Since 1990, transcatheter pulmonary valvotomy, using laser or radiofrequency heated guide wires followed by balloon dilation, has been introduced in our unit as an alternative to surgical valvotomy for pulmonary valve atresia and intact ventricular septum. ${ }^{18,19}$ In this report, we describe the growth of the right ventricle as assessed by echocardiography after successful pulmonary valvotomy.

\section{Methods}

Patients. Between April 1990 and April 1995, 15 consecutive neonates and infants were admitted to our unit with pulmonary valve atresia and intact ventricular sep- 
tum. Of these, 12 patients had cardiac catheterization to attempt transcatheter pulmonary valvotomy as a primary intervention, after fully informed consent had been obtained. The criteria for attempting catheter valvotomy included valvular atresia, a coronary circulation not dependent on the right ventricle, and confluent pulmonary arteries. In three patients, transcatheter intervention was not performed because the right ventricle was considered too small in one, the parents opted for a systemicpulmonary artery shunt in one, and the coronary artery was right ventricle-dependent in one. Furthermore, those patients with any evidence of flow through the pulmonary valve, according to either color Doppler echocardiography or angiography, were excluded from the study and treated by conventional balloon dilation. In all 12 patients, the arterial duct was maintained open before the procedure with an infusion of prostaglandin $\mathrm{E}_{2}$. The median age at the time of the procedure was 9 days (range 1 to 74 days), the median weight $3.06 \mathrm{~kg}$ (range $0.8 \mathrm{~kg}$ to $4.15 \mathrm{~kg}$ ), and the median body surface area (BSA) $0.21 \mathrm{~m}^{2}$ (range 0.11 $\mathrm{m}^{2}$ to $0.25 \mathrm{~m}^{2}$ ). In three of the patients the diagnosis of pulmonary valve atresia had been made prenatally.

Procedure. Cardiac catheterization was performed with general anesthesia in all the patients. The femoral artery and vein were cannulated percutaneously in all except one patient who required a cutdown onto the left femoral vein and cannulation of the umbilical artery (preterm baby weighing $800 \mathrm{gm})$. Heparin $(30 \mathrm{U} / \mathrm{kg}$ ) was administered once the vascular access was obtained. Usually a 4F sheath was inserted in the femoral artery and a 5F sheath in the femoral vein. The technique of pulmonary valvotomy has been described in detail previously. ${ }^{18,19}$ In the first six patients, laser-assisted valvotomy was performed with an 0.018 -inch laser guide wire. ${ }^{18}$ In the last five patients, radiofrequency-assisted valvotomy was performed with the use of an 0.020-inch or an 0.018-inch radiofrequency guide wire. ${ }^{19}$ In one patient, both laser and radiofrequency wires were used. Once the wire had perforated the atretic valve, subsequent balloon dilation of the valve was performed with balloons of progressively increasing size up to the valve anulus diameter. In four patients the arterial duct was also dilated with a balloon during the same procedure to improve the oxygen saturations, and in one patient the dysplastic, poorly mobile tricuspid valve on echocardiography was also dilated during the same procedure.

Postcatheter management. After completion of the procedure, the patients were kept in the intensive care unit and progressively weaned from ventilation and prostaglandin infusion when the oxygen saturations were satisfactory. In the patients who remained severely hypoxic immediately after the procedure despite prostaglandin infusion (oxygen saturations below $65 \%$ or desaturations with acidosis) or in the patients who remained prostaglandin-dependent up to 1 month after the procedure, further interventions were considered, such as balloon dilation of the arterial duct, stenting of the arterial duct, repeat balloon dilation of the right ventricular outflow tract, or insertion of a modified Blalock-Taussig shunt. These patients are referred to in the text as "remaining prostaglandin-dependent." In patients in whom the catheter valvotomy procedure had failed, sur- gical pulmonary valvotomy or modified Blalock-Taussig shunt insertion was considered.

Follow-up. After discharge from the hospital, the patients were reviewed regularly, usually with an assessment of oxygen saturation and cross-sectional echocardiography. Further cardiac catheterizations with or without intervention and surgical interventions were performed when clinically indicated.

Assessment of right ventricular size and growth. All the cross-sectional echocardiograms were retrospectively reviewed by one person (C.O.). The largest diameter of the tricuspid valve and the mitral valve anulus were measured in diastole from the apical four-chamber view. The tricuspid valve dimensions were expressed as Zvalues using the nomograms based on the published echocardiographic data. ${ }^{20,21}$ The transformation of a dimension into a $\mathrm{Z}$-value is based on the following equation $^{21}$ :

$$
\text { Z-value }=\frac{\text { Observed dimension }- \text { Mean normal dimension }}{\text { Standard deviation around mean normal dimension }}
$$

The ratio of the tricuspid valve to BSA was used as an alternative for relating the tricuspid valve dimensions to growth. The ratio of the tricuspid valve to the mitral valve was also calculated.

Data analysis. The 12 patients were divided into three groups according to their outcome. Group 1 consisted of patients who survived after successful transcatheter valvotomy $(n=6)$; group 2 comprised patients who died after successful transcatheter valvotomy $(n=3)$; and group 3 was composed of patients who died after unsuccessful transcatheter valvotomy $(n=3)$. The results are expressed as medians with ranges. To compare initial data with follow-up data, we used a paired Student's $t$ test.

\section{Results}

Short-term results. Successful perforation of the pulmonary valve and subsequent balloon dilation was achieved in nine (75\%) of the 12 patients (Fig. $1)$. In three $(25 \%)$ of the 12 patients, catheter valvotomy was unsuccessful. In the first patient, the laser wire passed from the infundibulum into the pericardium causing cardiac tamponade, which responded to needle aspiration. The child underwent an urgent operation but died in the operating room of coronary artery air embolism. Coexistent infundibular atresia was noted. The second patient was a preterm baby weighing $800 \mathrm{gm}$, in whom venous and arterial access required the use of the umbilical artery and cutdown of the femoral vein. The pulmonary artery was perforated during the procedure and the child died of cardiac tamponade in the catheterization laboratory. Autopsy also showed coexisting infundibular atresia. In the last patient, both laser and radiofrequency wires were positioned in the outflow tract sequentially, but a stable position could not be obtained. The procedure was therefore 


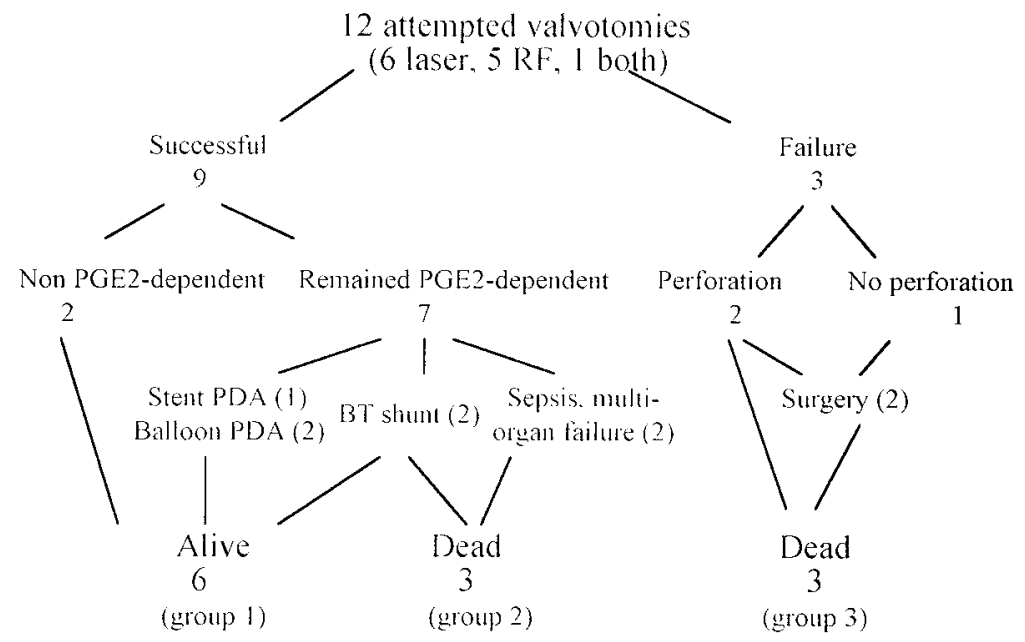

Fig. 1. Early results in the 12 neonates and infants with pulmonary atresia and intact ventricular septum in whom transcatheter pulmonary valvotomy was attempted as the initial treatment. $R F$, Radiofrequency; $P G E 2$, prostaglandin $\mathrm{E}_{2}, P D A$, patent arterial duct; $B T$ shunt, modified Blalock-Taussig shunt.

abandoned and the patient referred for surgical valvotomy 2 days later. After the valvotomy, the child remained deeply cyanotic. Surgical closure of the atrial septal defect was performed 24 hours later but the child died soon after returning to the intensive care unit.

Complications. In four of the nine patients in whom the pulmonary valve was successfully dilated, the main pulmonary artery was perforated by the laser or radiofrequency guide wire, resulting in cardiac tamponade in three and no hemodynamic effects in one. Surgical repair of the pulmonary artery perforation was required in only one of these patients; in the other two, cardiac tamponade was relieved by percutaneous pericardiocentesis before completion of the procedure. The patient in whom the pulmonary artery was perforated without cardiac tamponade also had a dissection of the femoral artery caused by the catheter, resulting in femoral artery occlusion. Heparin was not used after the procedure because of the pulmonary artery perforation, and the foot pulses returned to normal over the next 3 days.

Early outcome. Fig. 1 summarizes the outcome of the 12 patients after cardiac catheterization. Of the nine patients in whom the pulmonary valve had been successfully opened, two were successfully weaned from prostaglandin infusion 7 and 19 days after the valvotomy. These patients had the highest initial tricuspid $\mathrm{Z}$-values ( $\mathrm{Z}$-value $=-0.4$ for both). The other seven patients remained prostaglandin-dependent up to 1 month after the procedure. In three of these, additional transcatheter procedures were performed on the arterial duct. These included dilation of the arterial duct with a balloon 4 and 7 days after the catheter valvotomy in one patient and, in the second, 2 days after the valvotomy. In both of these patients, the arterial oxygen saturation improved and the prostaglandin infusion could be stopped. However, in the second patient, because of recurrent hypoxia, the duct was redilated 35 days after the catheter valvotomy when it was combined with balloon dilation of the right ventricular outflow tract and the tricuspid valve. In the third patient, a stent was implanted in the arterial duct in addition to repeat balloon dilation of the pulmonary valve 36 days after the initial catheter valvotomy, after which the prostaglandin infusion was stopped. A further two patients had modified Blalock-Taussig shunts inserted 5 and 9 days, respectively, after the valvotomy. One of these two continued to have persistent low arterial oxygen saturation despite the shunt and died of multiorgan failure and sepsis 18 days after the catheter valvotomy. In the other patient, the shunt operation was performed before the patient returned abroad. The two remaining patients, who were prostaglandin-dependent, had severe sepsis and multiorgan failure and died 6 and 33 days after the catheter valvotomy. The cross-sectional echocardiograms performed before death showed 
Table I. Comparison of the clinical and echocardiographic data at the time of catheter pulmonary valvotomy among the three groups

\begin{tabular}{lccc}
\hline & Group $1(n=6)$ & Group $2(n=3)$ & Group $3(n=3)$ \\
\hline Age (days) & $7.5(1$ to 51$)$ & $5(3$ to 10$)$ & $14(11$ to 75$)$ \\
Weight $(\mathrm{kg})$ & $2.9(2.1$ to 3.9$)$ & $3.2(2.7$ to 3.45$)$ & $3.2(0.8$ to 4.15$)$ \\
BSA $\left(\mathrm{m}^{2}\right)$ & $0.195(0.18$ to 0.24$)$ & $0.21(0.19$ to 0.22$)$ & $0.22(0.11$ to 0.25$)$ \\
TV anulus $(\mathrm{mm})$ & $10(8$ to 12$)$ & $8(8$ to 10$)$ & $7(3.5$ to 12.5$)$ \\
TV/BSA ratio & $48(41$ to 57$)$ & $-1.2(-1.5$ to -0.7$)$ & $32(31$ to 50$)$ \\
TV Z-value & $-0.8(-1.3$ to -0.4$)$ & $0.67(0.57$ to 0.67$)$ & -2.1 and $-0.7^{*}$ \\
TV/MV ratio & $0.615(0.56$ to 0.8$)$ & $0.5(0.35$ to 0.83$)$ \\
\hline
\end{tabular}

Results are expressed as medians for the groups with ranges in parentheses. $B S A$, Body surface area; $T V$, tricuspid valve; $M V$, mitral valve.

*Z-values are given for the two patients in group 3 for whom such values could be calculated.

unobstructed antegrade flow across the pulmonary valve, significant pulmonary and tricuspid regurgitation, and a right-to-left shunt at the atrial level.

Late outcome. Of the six surviving patients, one is being followed up abroad and is clinically well 8 months after catheter valvotomy and modified Blalock-Taussig shunt insertion, but no detailed echocardiographic data are available. The median follow-up for the other five is 60 months (range 37 to 68 months). Since discharge from the hospital, two of the five patients have required no further transcatheter or surgical intervention. In one of these two patients, a stent had been inserted in the arterial duct 36 days after the catheter valvotomy and before discharge. The stent was found to be occluded 2 years after insertion without any clinical deterioration or fall in oxygen saturation.

Three other patients have required further balloon dilation of the right ventricular outflow tract 3 to 45 months after the valvotomy; in one of them no other treatment was needed. In one, this was followed by surgical right ventricular outflow tract reconstruction with atrial septal defect closure 67 months after the initial catheter valvotomy, and one patient had surgical closure of an atrial septal defect 41 months after the catheter valvotomy. Thus two of the patients have required surgical closure of the atrial septal defect. At the latest follow-up, the systemic arterial oxygen saturation for the five patients ranged between $94 \%$ and $98 \%$, suggesting no significant right-to-left shunting. The Doppler gradients across the pulmonary valve ranged between 4 and $25 \mathrm{~mm} \mathrm{Hg}$. Mild pulmonary regurgitation was present in four and no pulmonary regurgitation in one. All of the five patients thus have two-ventricle circulation with the help of surgery in two and without any surgery in three.

\section{Growth of the right ventricle}

Initial tricuspid valve anulus measurements. Table I shows the clinical and echocardiographic data for the three groups of patients at the time of the initial cardiac catheterization. The tricuspid valve of one of the patients in group 3 was $3.5 \mathrm{~mm}$ and could not be expressed as a Z-value because no normal echocardiographic data exist for his BSA $\left(0.11 \mathrm{~m}^{2}\right)$.

Growth of the tricuspid valve anulus. Five of the six survivors have been followed up by serial cross-sectional echocardiography. In Fig. 2, the serial dimensions of the tricuspid valve, expressed in millimeters (Fig. 2,a), the tricuspid valve Z-values (Fig. 2, b), and the tricuspid/mitral valve ratios (Fig. 2,c) are related to BSA. In all patients, the absolute dimensions of the tricuspid valve increased with growth. However, in three of the patients, the absolute dimensions of the tricuspid valve diverged below 2 standard deviations from the mean derived from the normal data published by King and associates ${ }^{20}$ (Fig. 2, a). This was further confirmed by the $\mathrm{Z}$-values of the tricuspid valve growth, and therefore the right ventricular growth lagged behind the normal body growth. The ratio of the tricuspid valve to mitral valve dimensions showed a linear increase in four of the five patients, but in only one patient has the ratio reached 1.0 (Fig. 2, c). Table II compares the initial data, expressed as medians with ranges, in these five patients with those at the latest follow-up. There is a significant change in the tricuspid valve anulus, its Z-values, and the ratio of tricuspid valve to mitral valve.

All five patients have two-ventricle circulation, with or without additional surgery, despite smaller than normal tricuspid valve dimensions or Z-values.

\section{Discussion}

Initial treatment strategy. The management of neonates with pulmonary valve atresia and intact ventricular septum remains difficult because of the 
wide variations of the anatomy, such as the size and the morphology of the right ventricle and possible associated abnormalities of the coronary artery circulation. Treatment strategies have been influenced by these anatomic variations. ${ }^{3-6,8,9,11-13,15,17}$ In those patients with a severely hypoplastic bipartite right ventricle or a right ventricle-dependent coronary artery circulation, a systemic-pulmonary artery shunt is usually the initial treatment. In such cases, a two-ventricle circulation in the future is unlikely and a palliative approach such as the Fontan operation is preferred. When the coronary artery circulation is not dependent on the high-pressure right ventricle or when the right ventricle is of a "reasonable" size and has an infundibulum, early opening of the right ventricular outflow tract has been advocated to try to stimulate growth of the right ventricle. In such cases, the usual approach is a surgical valvotomy or right ventricular outflow tract patch with or without an additional systemic-pulmonary artery shunt. The importance of obtaining adequate relief of the right ventricular outflow tract obstruction with low right ventricular pressures has been stressed to promote as much as possible regression of right ventricular hypertrophy and growth of the right ventricular cavity. ${ }^{4,17}$ A prospective, multicenter study between 1987 and 1991 reported by Hanley and associates ${ }^{5}$ showed survival after surgical valvotomy, with or without a shunt, to be influenced by the initial tricuspid valve $\mathrm{Z}$-value. For patients with an initial tricuspid valve $Z$-value of -2 or higher (similar to our population), survival at 6 months was at least $86 \%$ with shunts and $77 \%$ without shunts.

In 1991, transcatheter pulmonary valvotomy was first described by Qureshi and colleagues ${ }^{18}$ as an alternative to surgical valvotomy to establish antegrade flow in pulmonary valve atresia. Since then, the technical skills for this demanding procedure have improved, the indications have become more precise, and more centers have begun to use this approach. ${ }^{19,22-26}$ The current report includes the entire learning curve with regard to the selection of patients and the technique. This explains the high overall mortality and morbidity when compared with the current surgical results. ${ }^{5}$ Two of the patients in our series in whom the procedure failed were considered in retrospect to be unsuitable candidates for catheter valvotomy because of the presence of infundibular atresia. In addition, most procedural complications were encountered in our early experience. From the experience of other centers
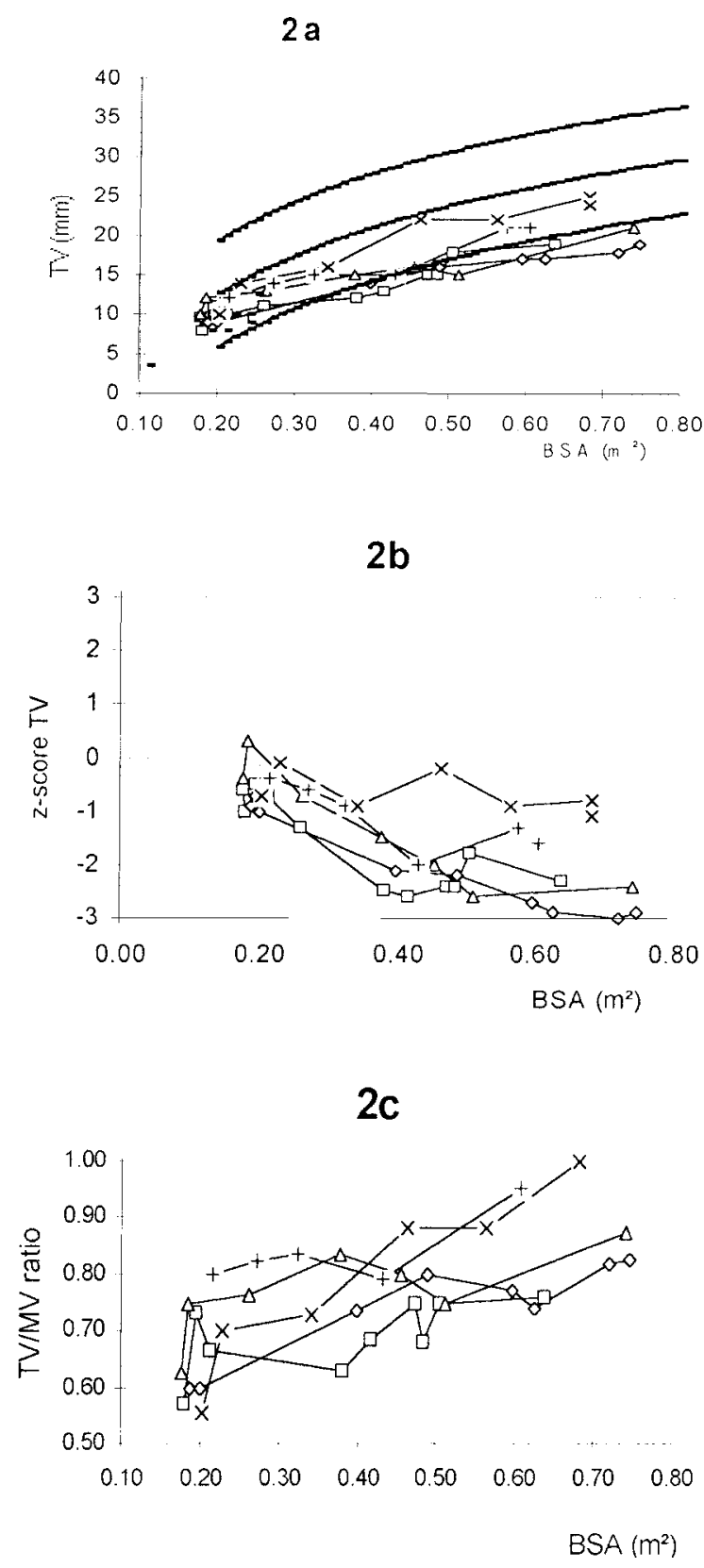

Fig. 2. Growth of the tricuspid valve as measured on serial cross-sectional echocardiograms in five of six survivors. a, Tricuspid valve (TV) dimensions, expressed in millimeters. Normal dimensions with mean and standard deviations, adapted from King's normal echocardiographic data ${ }^{20}$ are shown. b, Tricuspid valve Z-values. c, Tricuspid valve/mitral valve ratio $(T V / M V)$.

performing catheter valvotomy by these methods, it seems clear that the procedure can be considered as an alternative to surgical valvotomy, when the patients are carefully selected. ${ }^{24-28}$ Only those patients 
Table II. Comparison of initial echocardiographic data with data at latest follow-up examination in five of the six survivors

\begin{tabular}{lccc}
\hline & Initial data & Latest follow-up & $\begin{array}{c}p \\
\text { Values }\end{array}$ \\
\hline $\begin{array}{l}\text { TV anulus } \\
(\mathrm{mm})\end{array}$ & $10(8$ to 12$)$ & $21(19$ to 24$)$ & 0.00019 \\
TV Z-score & $-0.7(-1$ to -0.4$)$ & $-2.3(-1.1$ to -2.9$)$ & 0.0097 \\
TV/MV ratio & $0.6(0.56$ to 0.8$)$ & $0.88(0.76$ to 1$)$ & 0.01 \\
\hline
\end{tabular}

Values are expressed as medians with ranges in parentheses. $T V$, Tricuspid valve; $M V$, mitral valve.

with membranous valvular atresia and a patent infundibulum, in the setting of a non-right ventricledependent coronary circulation, should be considered for this procedure.

In addition to opening the right ventricular outflow tract, the need for a systemic-pulmonary shunt is an important question. The length of time that the pulmonary blood flow needs to be augmented by a shunt is not clear, because it is difficult, if not impossible, to judge when the right ventricle has become capable of supporting the pulmonary circulation on its own without the help of such a shunt. Kirklin and Barratt-Boyes ${ }^{1}$ estimated the freedom from systemic-pulmonary artery shunt 1 month after surgical valvotomy or pulmonary atresia to be $48 \%$ when the $\mathrm{Z}$-value of the tricuspid valve was -1 and $34 \%$ when the $\mathrm{Z}$-value was -2 . In our study, 1 month after catheter valvotomy, $33 \%(2 / 6)$ of the surviving patients were not duct-dependent. In our institution, we have attempted to avoid surgical shunts, when possible, to avoid distortion of the pulmonary arteries. Thus, of the four duct-dependent patients, only one had a surgical BlalockTaussig shunt, whereas the others had catheter approaches to maintain the arterial duct open. The advantage of such an approach is that the duct can close spontaneously over weeks or months after balloon dilation or even stent implantation, but by then, it appears as though the right ventricle has become capable of being the sole supply of pulmonary blood flow. Other centers performing this procedure may have lower thresholds and different indications for proceeding to a surgical or transcatheter shunt. $^{26}$

Assessment of right ventricular size. Inasmuch as the right ventricular volume is difficult to assess, tricuspid valve dimensions are generally used in the determination of treatment strategies. ${ }^{1,5}$ Different studies have reported that a good correlation exists between the dimension of the tricuspid valve and the size of the right ventricle in pulmonary atresia and intact ventricular septum. ${ }^{1,5,11} \mathrm{Z}$-values have been widely used to standardize dimensions and require reliable and representative normal values. ${ }^{21}$ Autop$\mathrm{sy}^{29}{ }^{29}$ echocardiographic, ${ }^{20}$ and angiographic ${ }^{30}$ data on tricuspid valves in normal children are available but differ substantially from each other. Several authors have used Z-values of tricuspid valves derived by echocardiography or angiography, but based on Rowlatt's autopsy data for their studies. ${ }^{4,5,21,29}$ It is difficult to compare measurements taken by different methods, and there is no clear correlation between autopsy and echocardiographic measurements with growth. Serial echocardiographic measurements are hard to interpret if they are expressed as Z-values based on autopsy data. Because of our serial echocardiographic measurements, we have opted to use echocardiographic measurements published by King and associates in calculating the Z-values. ${ }^{20}$

Growth of the right ventricle. The potential for growth of the right ventricle after valvotomy remains largely unknown and seems difficult to predict. Even severely hypoplastic ventricles may grow. ${ }^{13,15}$ In addition, it is impossible to judge the size of the right ventricle that will contribute to a successful two-ventricle circulation. Questions arise as to whether the initial size of the right ventricle is really important in the initial treatment strategy and whether the right ventricle needs to be of normal size to support the pulmonary circulation on its own. The minimal tricuspid valve $\mathrm{Z}$-value before catheter valvotomy in our study was -2.1 except in the preterm baby (800 gm), for whom echocardiographic normal Z-values are not available. Thus the right ventricle was of a "reasonable" size in all the patients. The tricuspid valve measurements, Z-values, and the ratio of the tricuspid valve to BSA tended to be smaller in groups 2 and 3 than in group 1 , suggesting that these children had more severe hypoplasia of the right ventricle. This supports the suggestion that the initial $\mathrm{Z}$-value of the tricuspid valve, and thus the size of the right ventricle, is likely to be a determinant of survival after valvotomy. ${ }^{5}$ In five of the six survivors, although the absolute tricuspid valve dimensions increased during followup, there was a trend toward deviation away from the normal range in three of the patients. The $\mathrm{Z}$-values of the tricuspid valve also decreased in most of the patients. Despite the subnormal size of the right ventricle, five of six children have twoventricle circulation. Therefore it appears as though 
normal tricuspid valve growth is not mandatory to have a right ventricle capable of sustaining the pulmonary circulation. Hanley and associates ${ }^{5}$ analyzed combined data from several studies on right ventricular growth after surgical treatment. ${ }^{6,12,13}$ This multivariate analysis indicated that the $\mathrm{Z}$-value of the tricuspid valve did not change during the follow-up period in patients in whom right ventricular-pulmonary artery continuity was established as the initial procedure. However, it is difficult to compare our data with the data of Hanley and coworkers, because their $\mathrm{Z}$-values were derived from autopsy measurements.

Limitations of our study. The small number of patients and the retrospective nature of the study are major limitations. No surgical control group is available with which to compare the results of the transcatheter approach. In addition, the patients do not cover the whole spectrum of pulmonary atresia and intact ventricular septum, and only the favorable end of the spectrum is seen with patients with initially reasonably good-sized right ventricles. No data are thus available on the potential for growth of "very small" right ventricles.

\section{Conclusion}

Transcatheter pulmonary valvotomy is an alternative treatment for neonates and infants with pulmonary valve atresia and intact ventricular septum, although proper selection of patients is required. The technique allows growth of the right ventricle and makes it possible for the patients to have two-ventricle circulation, even when right ventricular growth is suboptimal.

\section{REFERENCES}

1. Kirklin JW, Barratt-Boyes BG, editors. Pulmonary atresia and intact ventricular septum. 2nd ed. New York: Churchill Livingstone; 1993.

2. Coles JG, Freedom RM, Lightfoot NE, et al. Long-term results in neonates with pulmonary atresia and intact ventricular septum. Ann Thorac Surg 1989;47:213-7.

3. Pawade A, Capuani A, Penny DJ, Karl TR, Mee RBB. Pulmonary atresia with intact ventricular septum: surgical management based on right ventricular infundibulum. J Card Surg 1993;89:371-83.

4. Bull C, Kostelka M, Sorensen K, de Leval M. Outcome measures for the neonatal management of pulmonary atresia with intact ventricular septum. J Thorac Cardiovasc Surg 1994;107:359-66.

5. Hanley FL, Sade RM, Blackstone EH, Kirklin JW, Freedom RM, Nanda NC. Outcomes in neonatal pulmonary atresia with intact ventricular septum: a multiinstitutional study. J Thorac Cardiovasc Surg 1993;105:406-27.

6. de Leval M, Bull C, Stark J, Anderson RH, Taylor JFN,
Macartney FJ. Pulmonary atresia and intact ventricular septum: surgical management based on a revised classification. Circulation 1982;66:272-80.

7. Akagi T, Benson LN, Williams WG, Trusler GA, Freedom RM. Ventriculo-coronary arterial connections in pulmonary atresia with intact ventricular septum, and their influences on ventricular performance and clinical course. Am J Cardiol 1993;72:586-90.

8. Lightfoot NE, Coles JG, Dasmahapatra HK, et al. Analysis of survival in patients with pulmonary atresia and intact ventricular septum treated surgically. Int J Cardiol 1989;24:159-64.

9. Mainwaring RD, Lamberti JJ. Pulmonary atresia with intact ventricular septum: surgical approach based on ventricular size and coronary anatomy. J Thorac Cardiovasc Surg 1993; 106:733-8.

10. Giglia TM, Mandell VS, Connor AR, Mayer JE, Lock JE. Diagnosis and management of right ventricle-dependent coronary circulation in pulmonary atresia with intact ventricular septum. Circulation 1992;86:1516-28.

11. Bull C, de Leval M, Mercanti C, Macartney FJ, Anderson RH. Pulmonary atresia and intact ventricular septum: a revised classification. Circulation 1982;66:266-72.

12. Patel RG, Freedom RM, Moes CAF, et al. Right ventricular volume determinations in 18 patients with pulmonary atresia and intact ventricular septum: analysis of factors influencing right ventricular growth. Circulation 1980;2:428-40.

13. Hanseus K, Bjorkhem G, Lundstrom NR, Laurin S. Crosssectional echocardiographic measurements of right ventricular size and growth in patients with pulmonary atresia and intact ventricular septum. Pediatr Cardiol 1991;12:135-42.

14. Shaddy RE, Sturtevant JE, Judd VE, McGough EC. Right ventricular growth after transventricular pulmonary valvotomy and central aortopulmonary shunt for pulmonary atresia and intact ventricular septum. Circulation 1990;82:(Suppl): IV157-63.

15. Giglia TM, Jenkins KJ, Matitiau A, et al. Influence of right heart size on outcome in pulmonary atresia with intact ventricular septum. Circulation 1993;88(pt 1):2248-56.

16. Lewis $\mathrm{AB}$, Wells $\mathrm{W}$, Lindesmith GG. Right ventricular growth potential in neonates with pulmonary atresia and intact ventricular septum. J Thorac Cardiovasc Surg 1986;91: $835-40$.

17. Steinberger J, Berry JM, Bass JL, et al. Results of a right ventricular outflow patch for pulmonary atresia with intact ventricular septum. Circulation 1992;86:(Suppl):II167-75.

18. Qureshi SA, Rosenthal E, Tynan M, Anjos R, Baker EJ. Transcatheter laser-assisted balloon pulmonary valve dilation in pulmonic valve atresia. Am J Cardiol 1991;67:428-31.

19. Rosenthal E, Qureshi SA, Chan KC, et al. Radiofrequencyassisted balloon dilation in patients with pulmonary valve atresia and an intact ventricular septum. Br Heart J 1993;69: 347-51.

20. King DH, O’Brian Smith E, Huhta JC, Gutgesell HP. Mitral and tricuspid valve annular diameter in normal children determined by two-dimensional echocardiography. Am J Cardiol 1985;55:787-9.

21. Kirklin JW, Barratt-Boyes BG. Anatomy, dimensions, and terminology. In: Kirklin JW, Barratt-Boyes BG, editors. Pulmonary atresia and intact ventricular septum. 2nd ed. New York: Churchill Livingstone; 1993.

22. Parsons JM, Rees MR, Gibbs JL. Percutaneous laser valvotomy with balloon dilation of the pulmonary valve as 
primary treatment for pulmonary atresia. $\mathrm{Br}$ Heart $\mathrm{J}$ 1991;66:36-8.

23. Rosenthal E, Qureshi SA, Kadakekar AP, Anjos R, Baker EJ, Tynan M. Technique of percutaneous laser-assisted valve dilation for valvar atresia in congenital heart disease. $\mathrm{Br}$ Heart J 1993;69:556-62.

24. Gournay V, Piéchaud JF, Delogu A, Sidi D, Kachaner J. Balloon valvotomy for critical stenosis or atresia of pulmonary valve in newborns. J Am Coll Cardiol 1995;26: 1725-31.

25. Gibbs JL, Blackburn ME, Uzun O, Dickinson DF, Parsons JM, Chatrath RR. Laser valvotomy with balloon valvuloplasty for pulmonary atresia with intact ventricular septum: five years' experience. Heart 1997;77:225-8.

26. Justo RN, Nykanen DG, Williams WG, Freedom RM, Benson LN. Transcatheter perforation of the right ventricu- lar outflow tract as initial therapy for pulmonary valve atresia and intact ventricular septum in the newborn. Cathet Cardiovasc Diagn 1997;40:408-13.

27. Wright SB, Radtke WA, Gillette PC. Percutaneous radiofrequency valvotomy using a standard $5 \mathrm{Fr}$ electrode catheter for pulmonary atresia in neonates. Am J Cardiol 1996;77:1370-2.

28. Schneider M, Schranz D, Michel-Behnke I, Oelert H. Transcatheter radiofrequency perforation and stent implantation for palliation of pulmonary atresia in a 3060-g infant. Cathet Cardiovasc Diagn 1995;34:46-7.

29. Rowlatt JF, Rimoldi JHA, Lev M. The quantitative anatomy of the normal child's heart. Pediatr Clin North Am 1963;10: 499-588.

30. Alboliras ET, Julsrud PR, Danielson GK, et al. Definitive operation for pulmonary atresia with intact ventricular septum. J Thorac Cardiovasc Surg 1987;93:454-64.

\section{Bound volumes available to subscribers}

Bound volumes of The Journal of Thoracic and Cardiovascular Surgery are available to subscribers (only) for the 1998 issues from the Publisher, at a cost of $\$ 122.00$ for domestic, $\$ 151.94$ for Canadian, and $\$ 142.00$ for international subscribers for Vol. 115 (January-June) and Vol. 116 (July-December). Shipping charges are included. Each bound volume contains a subject and author index and all advertising is removed. Copies are shipped within 60 days after publication of the last issue of the volume. The binding is durable buckram with the Journal name, volume number, and year stamped in gold on the spine. Payment must accompany all orders. Contact Mosby, Inc., Subscription Services, 11830 Westline Industrial Drive, St. Louis, Missouri 63146-3318, USA; phone 800-453-4351 or 314-453-4351.

Subscriptions must be in force to qualify. Bound volumes are not available in place of a regular Journal subscription. 